\title{
Glomus tumor of the duodenum: a rare case report
}

\author{
Shin Sasaki ${ }^{*} \mathbb{D}$, Yuko Takami ${ }^{1}$, Yoshiyuki Wada ${ }^{1}$, Tomoki Ryu ${ }^{1}$, Hajime Imamura ${ }^{1}$, Hiroki Ureshino ${ }^{1}$, \\ Minako Fujiwara ${ }^{2}$ and Hideki Saitsu ${ }^{1}$
}

\begin{abstract}
Background: Glomus tumors (GTs) are mesenchymal neoplastic lesions arising from the glomus bodies and generally occur in the fingers and toes. Gastrointestinal GTs are rare, and most of them originate from the stomach; however, GT arising from the duodenum is exceedingly rare.

Case presentation: A 68-year-old man was admitted due to abdominal pain. Endoscopy showed a round, smooth, elevated mass in the second portion of the duodenum with central ulceration. Abdominal contrast computed tomography showed a hypervascular tumor measuring $26 \mathrm{~mm}$ in diameter in the second portion of the duodenum, and pancreatic invasion was suspected. Endoscopic ultrasonography of the lesion confirmed a hypoechoic mass arising from the fourth layer of the duodenal wall. A biopsy was performed for central ulceration, and immunochemical studies showed positive results for smooth muscle actin (SMA) and negative results for S100, C-Kit, and CD34. Leiomyoma or gastrointestinal stromal tumor was suspected and pancreatoduodenectomy was performed. The specimen exhibited a vascular-rich tumor, $24 \times 24 \times 19 \mathrm{~mm}$ in size, with deep ulceration in the duodenum. Histological examination showed uniform small round cells with central nuclei and a pale cytoplasm (glomus cell) with perivascular proliferation. Immunochemical studies showed that the tumor was positive for SMA and collagen type IV, and negative for C-Kit, CD34, desmin, and S100. We diagnosed the tumor as a GT of the duodenum.
\end{abstract}

Conclusion: GTs of the duodenum are exceedingly rare, but should be considered in the differential diagnoses of duodenal submucosal lesions.

Keywords: Duodenum, Glomus tumor, Submucosal tumor

\section{Background}

Glomus tumors (GTs) arise from the glomus bodies that act as skin thermoregulators, and are mostly found in the peripheral soft tissues at the dermal and subdermal subungual zones of fingers and toes [1]. Among the few reported cases, GTs arise from the gastrointestinal tract, and most of them originate from the stomach [2-5]. However, GTs arising from the duodenum are

\footnotetext{
*Correspondence: sasaki_shin@med.kurume-u.ac.jp; ureshino.hiroki.gd@mail. hosp.go.jp

${ }^{1}$ Department of Hepato-Biliary-Pancreatic Surgery, Clinical Research Institute, National Hospital Organization Kyushu Medical Center, 1-8-1 Jigyohama, Chuo-ku, Fukuoka 810-8563, Japan

Full list of author information is available at the end of the article
}

exceedingly rare. Here, we report a rare case of GT arising from the duodenum.

\section{Case presentation \\ Patient}

A 68-year-old man presented to his primary care physician with a complaint of abdominal pain. He had a medical history of reflux esophagitis and benign prostatic hyperplasia. Esophagogastroduodenoscopy was performed, which showed a submucosal mass in the second portion of the duodenum with central ulceration. Upon admission, his carcinoembryonic antigen (CEA) and carbohydrate antigen (CA) 19-9 levels were within normal limits. 


\section{Dynamic computed tomography (CT)}

Dynamic $\mathrm{CT}$ showed a circumscribed tumor measuring $26 \mathrm{~mm}$ in diameter in the second portion of the duodenum with ulceration. On the arterial and portal phase contrast-enhanced CT, the mass was greatly enhanced (Fig. 1a, b) with, persistent enhancement on the equilibrium phase (Fig. 1c). The mass was in contact with the pancreatic head, and pancreatic invasion was suspected. However, there was no dilatation of the central common bile duct and middle pancreatic duct.

\section{Magnetic resonance imaging (MRI)}

The T1-weighted image showed the tumor as a hypointensity (Fig. 2a), and the T2-weighted image showed a tumor with modestly high intensity (Fig. 2b). The tumor showed a slightly high intensity on diffusion-weighted imaging (DWI) (Fig. 2c), and the apparent diffusion coefficient (ADC) map displayed slight visual intensity.

\section{Esophagogastroduodenoscopy and endoscopic ultrasonography (EUS)}

Endoscopy showed a round, smooth, elevated mass in the second portion of the duodenum with central ulceration
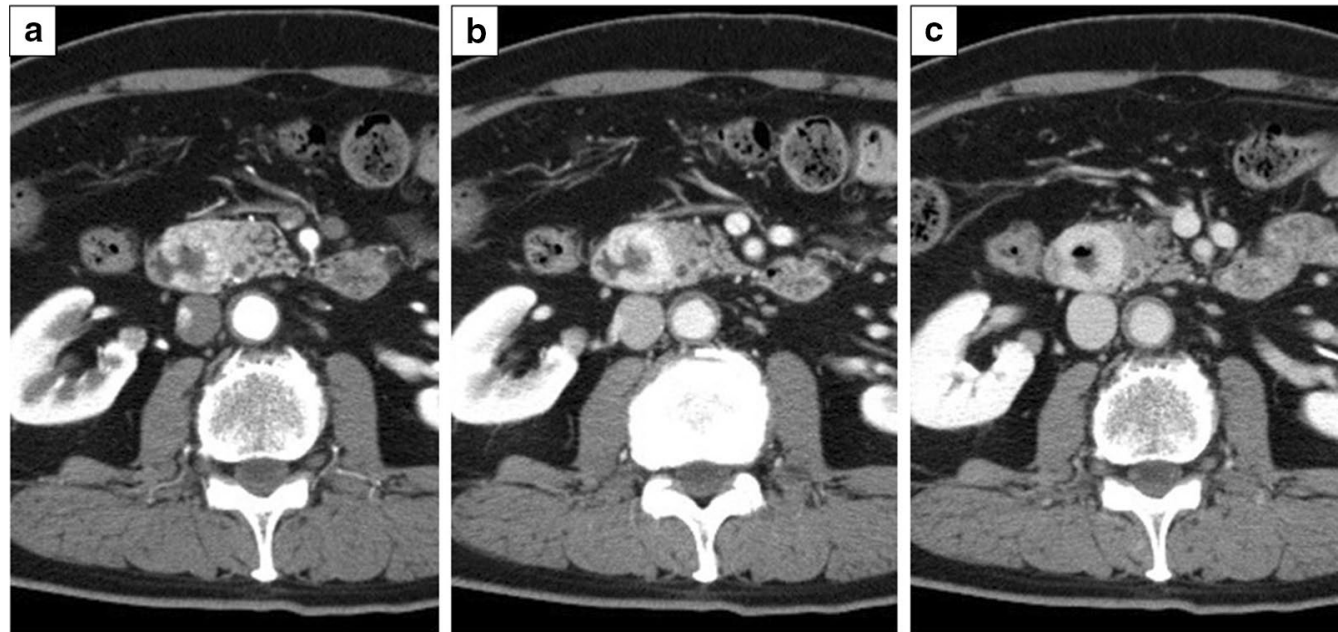

Fig. 1 Dynamic computed tomography (CT) shows a circumscribed tumor measuring $26 \mathrm{~mm}$ in diameter with ulceration in the second portion of the duodenum. $\mathbf{a}, \mathbf{b}$ On arterial (a) and portal phase (b) of contrast-enhanced $\mathrm{CT}$, the mass reveals significant enhancement. $\mathbf{c}$ The mass shows persistent enhancement on the delay phase
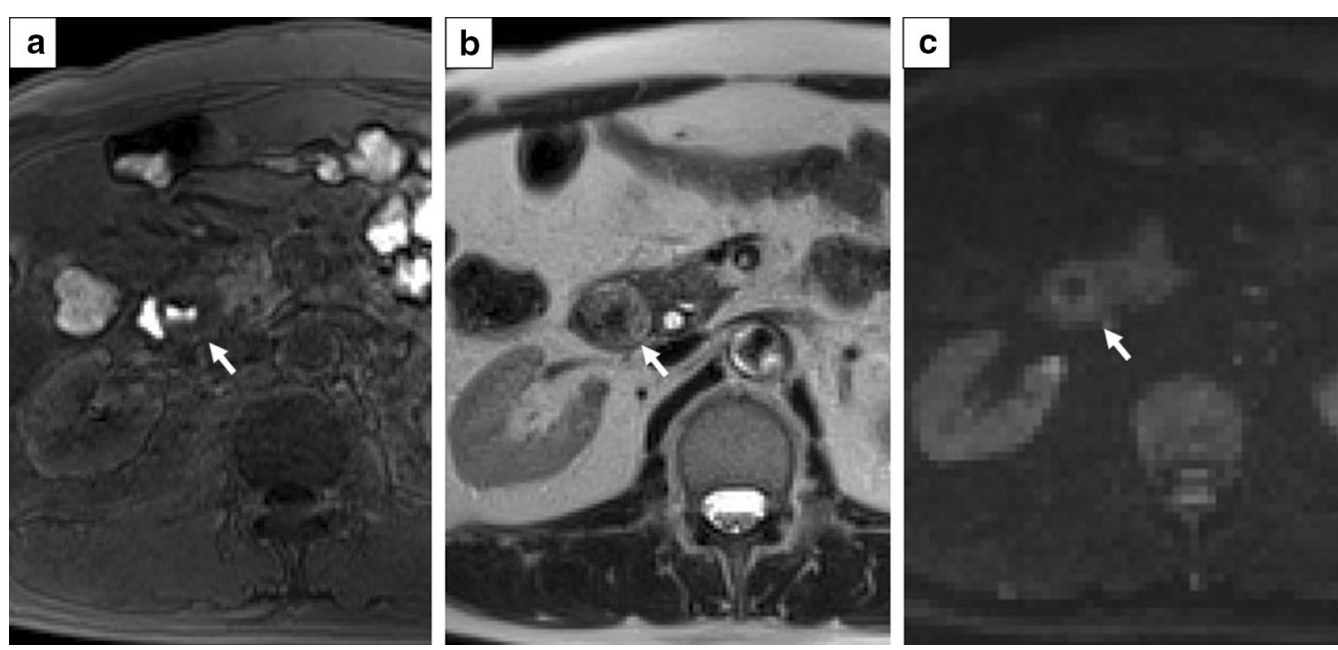

Fig. 2 a The tumor revealed hypo-intensity on T1-weighted image. b The tumor shows a modestly high intensity on T2-weighted imaging. c The tumor shows a slightly high intensity on diffusion-weighted images 
(Fig. 3a). Endoscopic ultrasonography of the lesion confirmed a hypoechoic mass arising from the fourth layer of the duodenal wall (Fig. 3b). A biopsy was performed from the central ulceration, but the cytological findings revealed no malignancy. Immunochemical studies were positive for smooth muscle actin (SMA) and negative for S100, C-Kit, and CD34.

Preoperatively, we diagnosed the tumor as a leiomyoma or gastrointestinal stromal tumor (GIST). Therefore, after informed consent was obtained, pancreatoduodenectomy (PD) was performed.

\section{Macroscopic findings}

The resected specimen showed a yellowish-white tumor, $24 \times 24 \times 19 \mathrm{~mm}$ in diameter, arising from the submucosa of the duodenal wall with deep ulceration (Fig. 4). The tumor was located at the oral site from the papilla of Vater and showed transmural growth in the duodenal wall.

\section{Histological findings}

The tumor was a vascular-rich tumor without capsular and deep ulceration (Fig. 5a). The lesion was shown by the nested or perivascular proliferation of mildly atypical cells with round-to-oval nuclei and eosinophilic cytoplasm (glomus cell), accompanied by prominent small blood vessels, hemorrhage and hyalinized stroma (Fig. 5b). The resected pancreas was free of tumor cells. No mitosis was observed. Immunochemical studies showed that the tumor was positive for SMA (Fig. 6a) and collagen type IV, and negative for C-Kit, CD34, desmin, and S100. The Ki-67 labeling index was $4 \%$ in the hot spot (Fig. 6b). As a result, the tumor was diagnosed

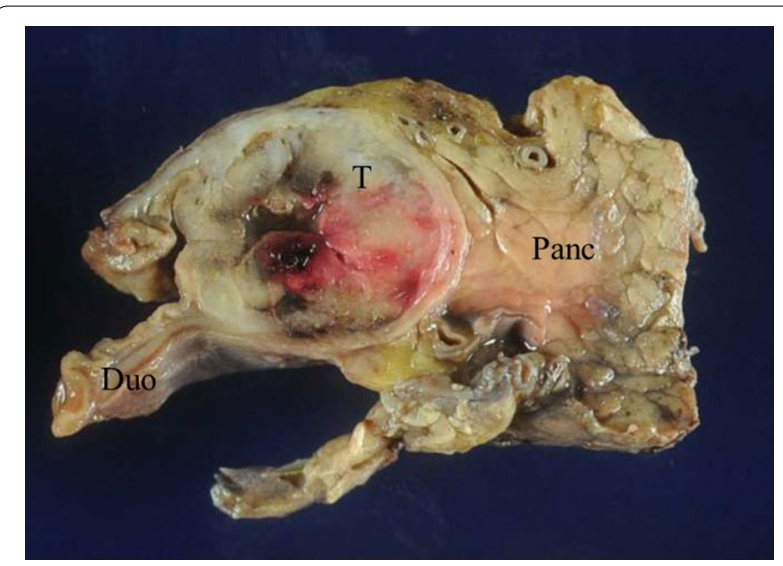

Fig. 4 The resected specimen shows a yellowish-white tumor, $24 \times 24 \times 19 \mathrm{~mm}$ in diameter, arising from the submucosa of the duodenal wall with deep ulceration. T tumor, Duo duodenum, Panc pancreas

as GT arising from the duodenum. There was no evidence of malignancy.

\section{Outcome}

The patient was discharged from the hospital 38 days after the surgery. No sign of recurrence was found after a year of surgery.

\section{Discussion}

GTs are rare benign neoplastic lesions arising from the glomus body, which is a component of skin thermoregulation [1]. GTs generally arise from the subungual zones of the fingers and toes; however, among the few reported cases, GTs have been reported to arise from the
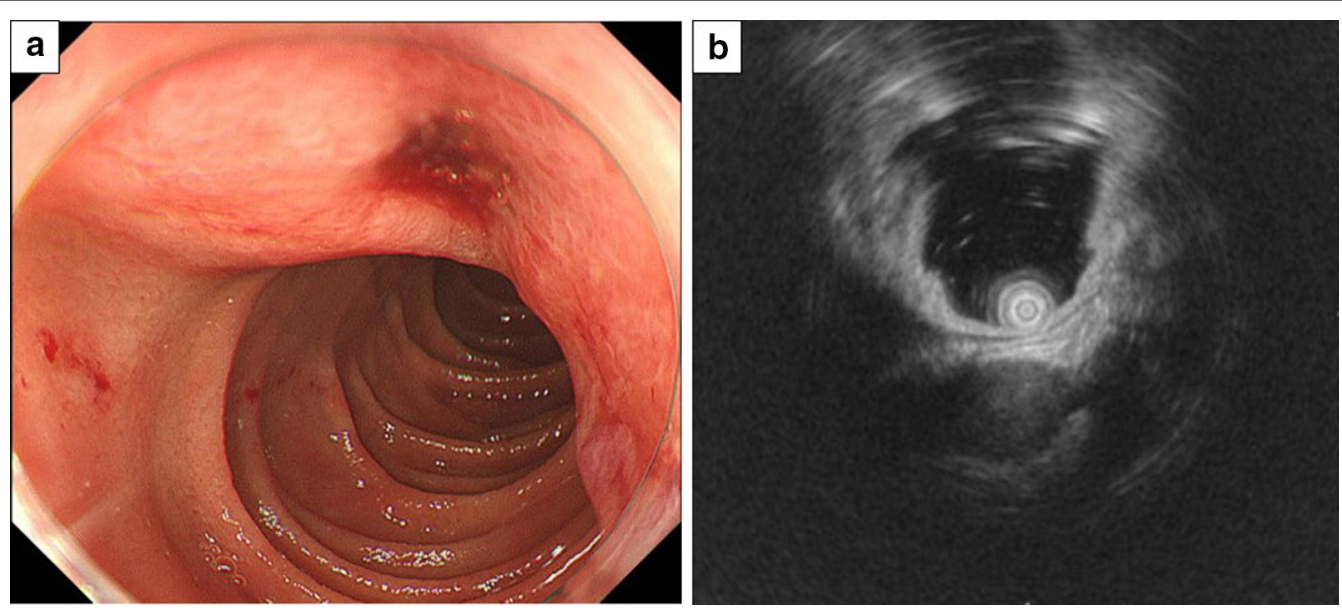

Fig. 3 a Endoscopy shows a round, smooth, elevated mass in the second portion of the duodenum with central ulceration. $\mathbf{b}$ Endoscopic ultrasonography of the lesion confirms a hypoechoic mass arising from the fourth layer of the duodenal wall 

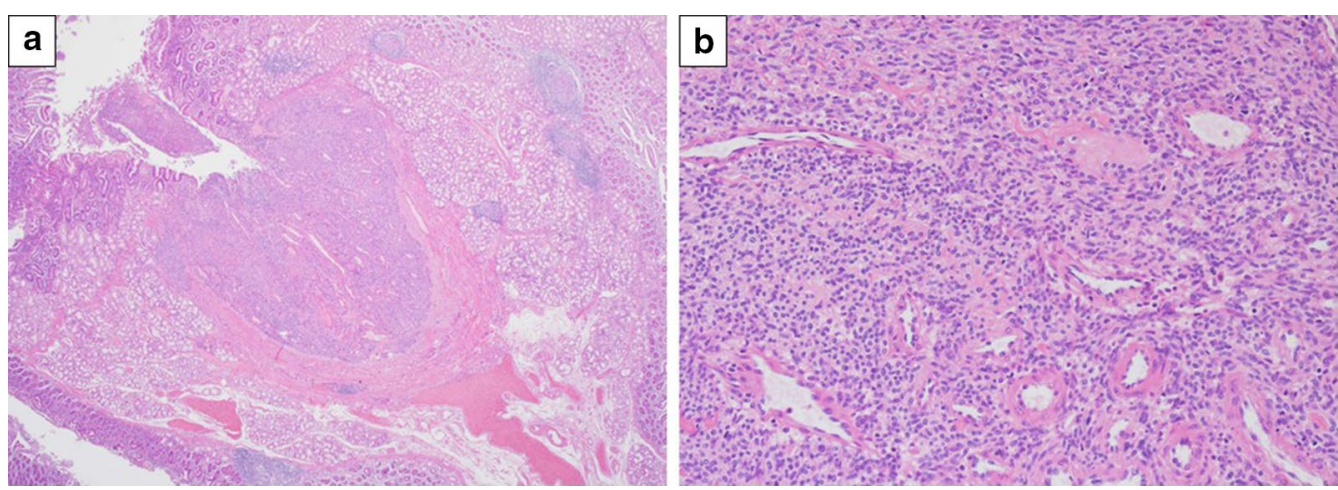

Fig. 5 Histological examination shows uniform small round cells with central nuclei and a pale cytoplasm (glomus cell) with perivascular proliferation. a Hematoxylin and eosin stain $(\times 2)$. b Hematoxylin and eosin stain $(\times 20)$
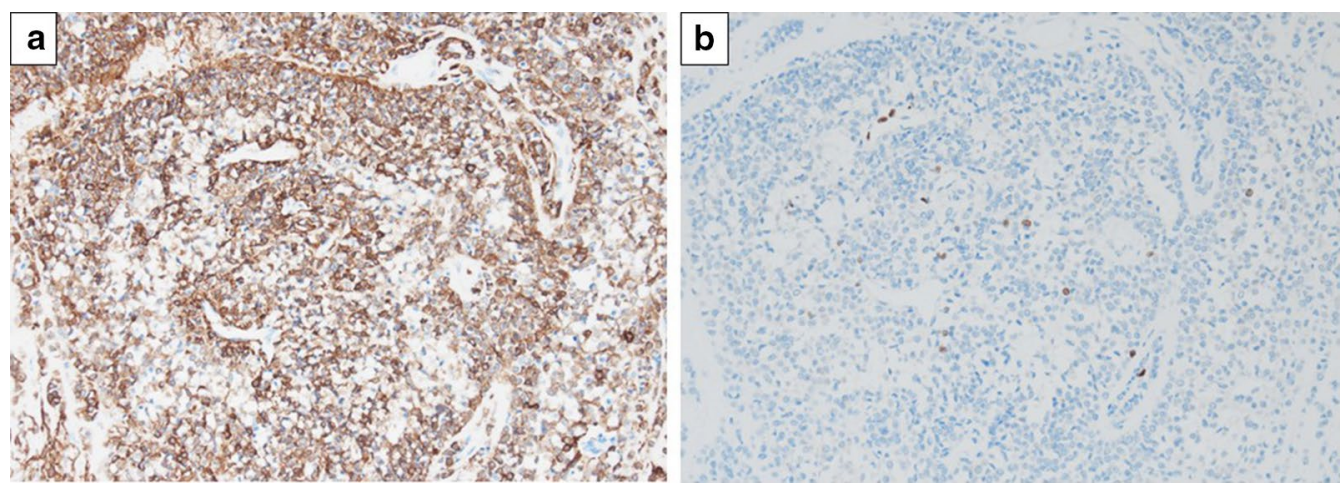

Fig. 6 a Immunochemical studies shows that the tumor was positive for smooth muscle actin. b Ki-67 labeling index was $4 \%$ in the hot spot

gastrointestinal tract and most of them from the stomach [3-5]. Gastric GT was first reported by Kay et al. in 1951[2] and is a rare disease accounting for approximately $1 \%$ of gastric mesenchymal tumors [5]. However, $\mathrm{GT}$ arising in the duodenum is exceedingly rare. In our search of the medical literature using PubMed with keywords "glomus tumor" and "duodenum", we found only 7 cases reported in English literature, and 2 cases were reported in the Russian medical literature. A review of English literature, including our case, is presented in Table 1 [6-12]. There are 5 males and 2 females, with a median age of $57(42-88)$ years. Most cases presented with gastrointestinal bleeding. In our literature review, there was no case that describes the medical history of GT of fingers and toes; we do not consider that patients with finger and toe GTs are at high risk for duodenal GTs. Since gastrointestinal GTs are rare, preoperative diagnosis is difficult. The differential diagnosis may include GIST, leiomyoma, neuroendocrine tumor (NET), lymphoma, ectopic pancreas, hemangioma, and secondary metastasis [13]. In our case, we preoperatively diagnosed
GIST or leiomyoma. Because GTs have characteristic features of prominent vascular channels, they can be identified by dynamic CT. Hur BY et al. reported that a glomus tumor revealed strong enhancement on the arterial phase and prolonged enhancement on delayed phase (hemangioma-like enhancement) during dynamic CT [8]. GTs show more strong enhancement than other submucosal lesions in dynamic CT. Dynamic CT can contribute to the characterization of GTs. EUS is also useful for evaluating submucosal tumors. GTs show a round smooth mass usually arising from the third to fourth layer of the gastrointestinal wall, with varying internal echo patterns [14]. Furthermore, gastrointestinal GTs presented not only submucosal case, but have also been reported to bulge intraluminally to form a polypoid [3]. The usefulness of fluorodeoxyglucose (FDG)-positron emission tomography (PET)/CT in the GT is unclear. In some reports, FDG-PET/CT was useful for detecting lesion [15], but in the contrast, in some cases FDG-PET/CT did not show a significant uptake at the lesion [16]. Other benign gastric submucosal tumors were also reported to 
Table 1 Literature review of case reports involving duodenum glomus tumor

\begin{tabular}{|c|c|c|c|c|c|c|c|c|}
\hline $\begin{array}{l}\text { Author } \\
\text { Year }\end{array}$ & Age & Gender & Chief complaints & Initial diagnosis & Tumor size $(\mathrm{cm})$ & $\begin{array}{l}\text { Tumor location } \\
\text { of the duodenum }\end{array}$ & Treatment & Prognosis \\
\hline $\begin{array}{l}\text { Jundi M } \\
2004\end{array}$ & 46 & Male & Melena & ND & $2.3 \times 1.5 \times 1.5$ & Second portion, & $\begin{array}{l}\text { Surgical resection } \\
\text { (not described } \\
\text { detail) }\end{array}$ & ND \\
\hline $\begin{array}{l}\text { Knackstedt C } \\
2007\end{array}$ & 65 & Male & $\begin{array}{l}\text { Vomiting } \\
\text { Upper gas- } \\
\text { trointestinal } \\
\text { bleeding }\end{array}$ & Glomus tumor & ND & Duodenal bulb & $\begin{array}{l}\text { Endoscopic } \\
\text { mucosal resec- } \\
\text { tion }\end{array}$ & $\begin{array}{l}\text { No signs of } \\
\text { recurrence at } \\
12 \text { months }\end{array}$ \\
\hline $\begin{array}{l}\text { Shelton JH } \\
2007\end{array}$ & 48 & Female & $\begin{array}{l}\text { Abdominal pain } \\
\text { Melena }\end{array}$ & $\begin{array}{l}\text { NET adenocarci- } \\
\text { noma }\end{array}$ & 3 & Ampulla of Vater & PD & ND \\
\hline $\begin{array}{l}\text { Hur BY } \\
2011\end{array}$ & ND & ND & ND & ND & $<4.4$ & $\begin{array}{l}\text { Duodenum (not } \\
\text { described detail) }\end{array}$ & ND & ND \\
\hline $\begin{array}{l}\text { Tarangelo NP } \\
2016\end{array}$ & 88 & Female & $\begin{array}{l}\text { Abdominal pain } \\
\text { Melena } \\
\text { Hematochezia }\end{array}$ & ND & $2.1 \times 1.4$ & Duodenal bulb & $\begin{array}{l}\text { Artery embo- } \\
\text { lization for } \\
\text { bleeding }\end{array}$ & ND \\
\hline $\begin{array}{l}\text { Sadidoust A } \\
2020\end{array}$ & 57 & Male & $\begin{array}{l}\text { Epigastric pain } \\
\text { Dyspepsia }\end{array}$ & ND & $1.2 \times 0.7$ & Second portion & $\begin{array}{l}\text { Endoscopic } \\
\text { mucosal resec- } \\
\text { tion }\end{array}$ & $\begin{array}{l}\text { No signs of } \\
\text { recurrence at } \\
48 \text { months }\end{array}$ \\
\hline $\begin{array}{l}\text { Yoon J } \\
2020\end{array}$ & 42 & Male & $\begin{array}{l}\text { Abdominal pain } \\
\text { Melena }\end{array}$ & ND & $2.5 \times 1.5$ & Third portion & $\begin{array}{l}\text { Laparoscopic } \\
\text { wedge resec- } \\
\text { tion }\end{array}$ & $\begin{array}{l}\text { No signs of } \\
\text { recurrence at } \\
18 \text { months }\end{array}$ \\
\hline Our case & 68 & Male & Abdominal pain & $\begin{array}{l}\text { GIST } \\
\text { Leiomyoma }\end{array}$ & $2.4 \times 2.4 \times 1.9$ & Second portion & PD & $\begin{array}{l}\text { No signs of } \\
\text { recurrence at } \\
12 \text { months }\end{array}$ \\
\hline
\end{tabular}

NET neuroendocrine tumor, GIST gastrointestinal stromal tumor, PD pancreatoduodenectomy, ND not described

exhibit FDG avidity [17]; FDG-PET/CT may have a limited value in terms of the diagnosis of GTs.

Histopathological findings showed uniform small basophilic round cells with central nuclei and pale eosinophilic cytoplasm (glomus cells) in alveolar hyperplasia around the small vessels. Immunohistochemical findings are useful for distinguishing GT from other subepithelial tumors. GT tumors are positive for SMA, vimentin, and collagen IV. In contrast, negative for C-Kit, CD34 (rarely positive), desmin, S100, and CD45 [3]. Most gastric GTs are benign, but malignant transformation has been reported in approximately $1 \%$ of all GTs [3]. Folpe et al. proposed the criteria for malignant GTs, including deep location and size greater than $2 \mathrm{~cm}$, atypical mitotic figures, moderate-to-high nuclear grade, and $\geq 5$ mitotic figures/50 HPF [18]. In our case, there were no mitotic figures, and the Ki-67 labeling index was $4 \%$ in the hot spot; these features were considered negative for malignancy. The prognosis of malignant GT of the duodenum remains enigmatic because of the scarcity of reported cases. There were no malignant GTs of the duodenum in our literature review. Although there is a report of malignant GT of the duodenum in the Russian literature, the case died from bleeding 23 days after the operation [19].

Treatment of duodenal GTs consists of endoscopic mucosal resection, laparoscopic wedge resection and PD (Table 1). Preoperatively, we suspected the tumor to be a leiomyoma based on immunochemical study of the tissue obtained from the tumor ulcer. However, since we did not perform EUS-fine needle aspiration (FNA), GIST was also suspected because of the possibility that the tissue was not adequate for diagnosis and imaging findings. Since the tumor was considered to have malignant potential (tumor size $>2 \mathrm{~cm}$ in diameter and with ulceration) and pancreatic invasion, we performed PD. Surgical treatment as a choice depends on the location and size of the tumor; in some reports, non-exposed endoscopic wall-inversion surgery (NEWS) and laparoscopic endoscopic cooperative surgery (LECS) have been used to resect gastrointestinal glomus tumor [20, 21].

\section{Conclusion}

We present a rare case of GT in the duodenum. Duodenal GTs are difficult to distinguish from other submucosal lesions in the duodenum; however, immunohistochemical staining helps determine the correct diagnosis, and dynamic CT aids in preoperative diagnosis. Furthermore, GTs of the duodenum are exceedingly rare, but should be considered in the potential diagnosis of a duodenal submucosal lesion.

\section{Abbreviations}

GTs: Glomus tumors; CT: Computed tomography; EUS: Endoscopic ultrasound; SMA: Smooth muscle action; GIST: Gastrointestinal stromal tumor; PD: 
Pancreatoduodenectomy; CEA: Carcinoembryonic antigen; CA19-9: Carbohydrate antigen 19-9; MRI: Magnetic resonance imaging; EUS: Endoscopic ultrasonography; DWI: Diffusion-weighted images; ADC: Apparent diffusion coefficient; FDG: Fluorodeoxyglucose; PET: Positron emission tomography; FNA: Fine needle aspiration; NEWS: Non-exposed endoscopic wall-inversion surgery; LECS: Laparoscopic endoscopic cooperative surgery.

\section{Acknowledgements}

We gratefully acknowledge the work of the members of our laboratory, and would like to thank Editage (www.editage.jp) for English language editing.

\section{Authors' contributions}

SS and YT drafted and revised the manuscript. SS, YT, YW, and HU participated in the surgery and contributed to perioperative care. MF performed the histopathological diagnosis. SS, YT, YW, TR and HI treated the patient in the outpatient clinic and during hospitalization. HS supervised the writing of the manuscript. All authors have read and approved the final version of the manuscript.

\section{Funding}

No funding was received for this article and the authors have no conflicts of interest directly relevant to this report.

\section{Availability of data and materials}

Data will be made available from the corresponding author upon request.

\section{Ethics approval and consent to participate}

All procedures involving human participants were in accordance with the ethical standards of the Institutional Review Board of the National Hospital Organization Kyushu Medical Center. Informed consent was obtained from all participants.

\section{Consent for publication}

Written informed consent was obtained from the patient for publication of this case report and any accompanying images.

\section{Competing interests}

The authors declare that they have no competing interests.

\section{Author details}

${ }^{1}$ Department of Hepato-Biliary-Pancreatic Surgery, Clinical Research Institute, National Hospital Organization Kyushu Medical Center, 1-8-1 Jigyohama, Chuo-ku, Fukuoka 810-8563, Japan. ${ }^{2}$ Department of Pathology, National Hospital Organization Kyushu Medical Center, 1-8-1 Jigyohama, Chuo-ku, Fukuoka 810-8563, Japan.

Received: 6 October 2020 Accepted: 25 November 2020

Published online: 03 December 2020

\section{References}

1. Gombos Z, Zhang PJ. Glomus tumor. Arch Pathol Lab Med. 2008;132(9):1448-52.

2. Kay S, Callahan WP Jr, Murray MR, Randall HT, Stout AP. Glomus tumors of the stomach. Cancer. 1951;4(4):726-36.
3. Miettinen M, Paal E, Lasota J, Sobin LH. Gastrointestinal glomus tumors: a clinicopathologic, immunohistochemical, and molecular genetic study of 32 cases. Am J Surg Pathol. 2002;26(3):301-11.

4. Thambi R, Sheeja S, Joesph CP, Poothiode U. Gastric glomus tumor: a brief report. Indian J Pathol Microbiol. 2014;57(3):509-10.

5. Vassiliou I, Tympa A, Theodosopoulos T, Dafnios N, Fragulidis G, Koureas A et al. Gastric glomus tumor: a case report. World J Surg Oncol. 2010;8:19.

6. Yoon J, Kim K, Lee S. Imaging findings of glomus tumor at duodenum: a case description. Quant Imaging Med Surg. 2020;10(5):1133-7.

7. Sadidoust A, Anbardar MH, Lankarani KB. Endoscopic mucosal resection of a glomus tumour of the duodenum. Prz Gastroenterol. 2020;15(2):173-4.

8. Hur BY, Kim SH, Choi JY, Rha SE, Lee MW, Kim SY, et al. Gastroduodenal glomus tumors: differentiation from other subepithelial lesions based on dynamic contrast-enhanced CT findings. AJR Am J Roentgenol. 2011;197(6):1351-9.

9. Shelton JH, Lamont JP, Zieske A, Mallat DB. Glomus tumor of the ampulla. Gastrointest Endosc. 2007:66(2):395-96; discussion 396.

10. Knackstedt C, Wasmuth H, Donner A, Trautwein C, Winograd R. Diagnosis of an unusual tumor in the duodenum. Endoscopy. 2007:39(Suppl 1):E94.

11. Jundi M, Lack EE, Brun EA, Esquivel J, Kumar D. Glomus tumor of the duodenum: a case report. Int J Surg Pathol. 2004;12(4):411-4.

12. Tarangelo NP, Ha K, Skole KS. Duodenal glomus tumor: a rare cause of upper Gl bleeding. Clin Gastroenterol Hepatol. 2016:14(10):e123-124.

13. Latos W, Kawczyk-Krupka A, Strzelczyk N, Sieroń A, Cieślar G. Benign and non-neoplastic tumours of the duodenum. Prz Gastroenterol. 2019:14(4):233-41.

14. Imamura A, Tochihara M, Natsui K, Murashima Y, Suga T, Yaosaka T, et al. Glomus tumor of the stomach: endoscopic ultrasonographic findings. Am J Gastroenterol. 1994;89(2):271-2.

15. Shao D, Gao Q, Wang S, Cheng Y, Wang S. 18F-FDG PET/CT of benign tracheal glomus tumor. Clin Nucl Med. 2020;45(2):141-2.

16. Santambrogio L, Nosotti M, Palleschi A, Gazzano G, De Simone M, Cioffi U. Primary pulmonary glomangioma: a coin lesion negative on PET study. Case report and literature review. Thorac Cardiovasc Surg. 2011;59(6):380-82

17. Yoo J, Kim SH, Han JK. Multiparametric MRI and (18)F-FDG PET features for differentiating gastrointestinal stromal tumors from benign gastric subepithelial lesions. Eur Radiol. 2020;30(3):1634-43.

18. Folpe AL, Fanburg-Smith JC, Miettinen M, Weiss SW. Atypical and malignant glomus tumors: analysis of 52 cases, with a proposal for the reclassification of glomus tumors. Am J Surg Pathol. 2001;25(1):1-12.

19. Leĭkina MA, Averbakh AM. Malignant glomic tumor of the duodenum. Arkh Patol. 1984;46(10):81-4.

20. Ebi M, Sugiyama T, Yamamoto K, Saito T, Inoue T, Yamaguchi Y, et al. A gastric glomus tumor resected using non-exposed endoscopic wallinversion surgery. Clin J Gastroenterol. 2017;10(6):508-13.

21. Aoba T, Kato T, Hiramatsu K, Shibata Y, Yoshihara M, Yamaguchi N, et al. A case of gastric glomus tumor resection using laparoscopy endoscopy cooperative surgery (LECS). Int J Surg Case Rep. 2018;42:204-7.

\section{Publisher's Note}

Springer Nature remains neutral with regard to jurisdictional claims in published maps and institutional affiliations. 